\title{
NOTE ON TRANSLITERATION AND TRANSLATION
}

Titles of books, periodicals, and concepts in Armenian, Arabic, Hebrew, Greek, Ladino, Ottoman Turkish, Russian, and Turkish are transliterated according to the Library of Congress Transliteration System. Except for the translations from Greek, done by Andreas Batalas and Alexandra Stamadianou, all translations are mine. 
This page intentionally left blank 
THE HORRORS OF ADANA 
This page intentionally left blank 